\title{
Improved Czochralski Growth of Germanium Single Crystals from a Melt Covered by Boron Oxide
}

\author{
T. TAISHI ${ }^{a, *}$, I. YONENAGA $^{b}$ AND K. HoshiKAWA ${ }^{a}$ \\ ${ }^{a}$ Faculty of Engineering, Shinshu University, Wakasato, Nagano 380-8553, Japan \\ ${ }^{b}$ Institute for Materials Research, Tohoku University, Katahira, Aoba-ku, Sendai, 980-8557, Japan \\ In germanium $(\mathrm{Ge})$ crystal growth, a serious problem in growing high quality Ge crystals is the formation of \\ germanium-oxide-particles on the melt surface. In addition, B doping in Ge crystals is very difficult because of the \\ segregation coefficient, which is greater than unity, and the instability of free B atoms in the Ge melt. We have \\ found a unique solution, which is CZ-Ge crystal growth from a melt covered by boron oxide $\left(\mathrm{B}_{2} \mathrm{O}_{3}\right)$. Ge crystals \\ which are dislocation-free and/or oxygen-enriched can be grown by these improved $\mathrm{CZ}$ techniques. Current and \\ planned research using such Ge crystals is introduced.
}

DOI: 10.12693/APhysPolA.124.231

PACS: $81.10 . \mathrm{Fq}, 61.72 . \mathrm{Ff}, 61.72 . u f$

\section{Introduction}

A crystal growth technique proposed by Jan Czochralski, the so-called Czochralski (CZ) method [1], has been widely applied for growing various types of single crystals such as silicon $(\mathrm{Si})$, germanium $(\mathrm{Ge})$ and oxide materials in industry. In fact, if this growth method had not been discovered, the current development of Si technology using large-scale dislocation-free crystals would not be possible. In addition, for growing III-V semiconductors such as GaAs, GaP, and InP, a liquid encapsulated Czochralski (LEC) technique has been developed [2-4]. Generally, boron oxide $\left(\mathrm{B}_{2} \mathrm{O}_{3}\right)$ has been used as a suitable liquid encapsulant to avoid the evaporation of volatile elements such as As and P from the melt. Concluding, growth techniques based on the $\mathrm{CZ}$ method have been improved so that they are practicable for growing single crystals.

In the following, $\mathrm{CZ}$ crystal growth of $\mathrm{Si}$ and $\mathrm{Ge}$ are compared with each other. In the case of CZ-Si crystal growth, a silica crucible is used [5]. Oxygen atoms are dissolved from the crucible by the contact with Si melt. Therefore the number of oxygen atoms in the grown crystals is enriched and, indeed, the interstitial oxygen concentration is generally $\approx 10^{18} \mathrm{~cm}^{-3}$. Such oxygen impurities have a positive use in enhancing the critical resolved shear stress for dislocation generation [6]. They lead to high mechanical strength in comparison with float-zone Si crystals $[7,8]$. In Si technology, boron (B) is generally used as a $p$-type dopant. On the other hand, in the case of CZ-Ge crystal growth, Ge crystals are generally grown using a graphite crucible in vacuum or inert gas $\left(\mathrm{N}_{2}\right.$ or Ar) atmosphere [9]. Therefore, the interstitial oxygen concentration in Ge crystals is very low. Recently, dislocation-free $\mathrm{Ge}$ single crystals up to $300 \mathrm{~mm}$ in di-

*corresponding author; e-mail: taishi@shinshu-u.ac.jp ameter have been grown for use as the substrate or the bottom cell of III-V based tandem solar cells [10, 11]. As a $p$-type dopant, highly volatile gallium or indium, rather than B, are used in Ge crystal growth.

In this paper, problems due to the formation of particles floating on the melt surface during CZ-Ge crystal growth are described. Next, we report improved CZ-Ge crystal growth techniques using $\mathrm{B}_{2} \mathrm{O}_{3}$ and a silica crucible, which can realize growth of dislocation-free and oxygen-enriched Ge crystals. The contamination levels of $\mathrm{B}$ from $\mathrm{B}_{2} \mathrm{O}_{3}$ liquid and of Si from the silica crucible in Ge crystals are very low. Based on these results, related reactions which occur during the growth are discussed. Finally, current and future research activities using $\mathrm{Ge}$ crystals grown by the improved $\mathrm{CZ}$ method are introduced.

\section{Particles floating on the melt surface during CZ-Ge crystal growth}

Germanium-oxide $\left(\mathrm{GeO}_{2}\right)$-related particles, which may arise from residual oxygen in the growth furnace or a thin oxide layer on the surface of Ge raw materials used to charge the crucible, are easily formed on the melt surface. The melting point of such particles $\left(1115^{\circ} \mathrm{C}\right)$ is higher than that of $\mathrm{Ge}\left(938^{\circ} \mathrm{C}\right)$, so these particles cannot be removed completely. They then attach themselves to the growing Ge crystal surface, as shown in Fig. 1a, eventually generating dislocations in the crystal around these locations. Dislocation-free crystal growth is therefore difficult because of the formation of $\mathrm{GeO}_{2}$-related particles in the melt.

In addition, previous studies [12] have shown that in the case of B-doped CZ-Ge crystal growth, when granular B had been added in the silica crucible along with the Ge raw materials, they could not be melted completely in the Ge melt. The unmelted B granules attached themselves to the seed at the beginning of the crystal growth, and the grown crystal became polycrystalline. The car- 


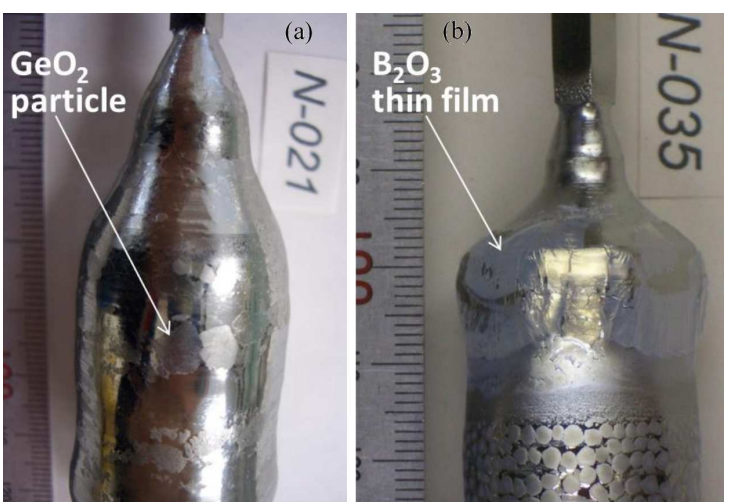

Fig. 1. Photographs of CZ-grown Ge crystals with particles attached. (a) $\mathrm{GeO}_{2}$-related particles, (b) $\mathrm{B}_{2} \mathrm{O}_{3}$ thin film attached to grown crystal surface during growth.

rier concentration in the top portion in such Ge crystals was about $3 \times 10^{18} \mathrm{~cm}^{-3}$, and it decreased with increasing solidified fraction [12]. Then, an equilibrium segregation coefficient of $\mathrm{B}$ in $\mathrm{Ge}$ of $k_{0}=6.2$ was estimated [13]. When Ge alloy containing $\mathrm{B}$ was added to the Ge melt, a thin white $\mathrm{B}_{2} \mathrm{O}_{3}$ film (rather than $\mathrm{GeO}_{2}$-related particles) developed on the melt surface and became attached to the grown crystal as shown in Fig. 1b. The top portion of the crystal exhibited $p$-type conduction, and the carrier concentration was $2 \times 10^{15} \mathrm{~cm}^{-3}$. However, the carrier type changed to $n$-type below the middle portion of the crystals, indicating that the $\mathrm{B}$ concentration decreased dramatically with increasing solidified fraction. These results indicate that $\mathrm{GeO}_{2}$-related particles are dissolved by free $\mathrm{B}$ atoms and then the free $\mathrm{O}$ atoms generated by the dissolution process react with other free $\mathrm{B}$ atoms to form $\mathrm{B}_{2} \mathrm{O}_{3}$. Therefore, $\mathrm{B}$ doping in the Ge crystal is very difficult, and $\mathrm{B}$ dopant is not used in Ge crystal growth.

\section{Growth of CZ-Ge crystals from melt partially covered by $\mathrm{B}_{2} \mathrm{O}_{3}$ liquid}

Based on the ability of $\mathrm{B}_{2} \mathrm{O}_{3}$ to dissolve $\mathrm{GeO}_{2}$-related particles and the stability of $\mathrm{B}_{2} \mathrm{O}_{3}$ in $\mathrm{Ge}$ melt, the $\mathrm{Ge}$ melt was partially covered by $\mathrm{B}_{2} \mathrm{O}_{3}$ and a Ge crystal was grown from this melt. Ge ingots with a purity of better than $4 \mathrm{~N}(\approx 150 \mathrm{~g})$ were put into a silica crucible $50 \mathrm{~mm}$ in diameter, and $\mathrm{B}_{2} \mathrm{O}_{3}$ chunks ( $5 \mathrm{~g}$ or $7.5 \mathrm{~g}$ ) were placed on the Ge ingots. [111] or [001]-oriented Ge crystals, 1 inch in diameter, were grown at a pulling rate of $10 \mathrm{~mm} / \mathrm{h}$ in argon atmosphere of 1 atm. Detailed growth conditions were as described previously [14]. After melting the $\mathrm{B}_{2} \mathrm{O}_{3}$ and $\mathrm{Ge}$, only the outside region of the Ge melt was partially covered with the liquid $\mathrm{B}_{2} \mathrm{O}_{3}$, and a clean and particle-free Ge melt surface was produced in the central region of the crucible. Figure 2 a shows a photograph taken during the crystal growth from the particle-free $\mathrm{Ge}$ melt. Figure 2b shows a [111]-oriented undoped Ge crystal grown from a $\mathrm{Ge}$ melt partially covered with $\mathrm{B}_{2} \mathrm{O}_{3}$.
It has a diameter of about 1 inch and a length of about $50 \mathrm{~mm}$. No particles were detected on the surface of the crystal. Three habit lines can be clearly observed. The crystal growth procedure was almost the same as that used in the conventional method except that the Ge melt was partially covered with $\mathrm{B}_{2} \mathrm{O}_{3}$ liquid. The dislocation density in a Ge crystal can be considerably reduced by using the technique described. In addition, no etch pits could be detected in [111] or [100]-oriented Ge crystals $[14,15]$. The crystal exhibited $n$-type conduction and no contamination by B and Si atoms could be detected by Hall-effect measurement, SIMS or infrared analysis. The interstitial oxygen concentration was $1.6 \times 10^{16} \mathrm{~cm}^{-3}$, which was slightly larger than that in a conventionally grown Ge crystal. Based on these results, we conclude that the growth from a partially- $\mathrm{B}_{2} \mathrm{O}_{3}$-covered melt is effective for growing [111] or [100]-oriented Ge crystals free from dislocations.
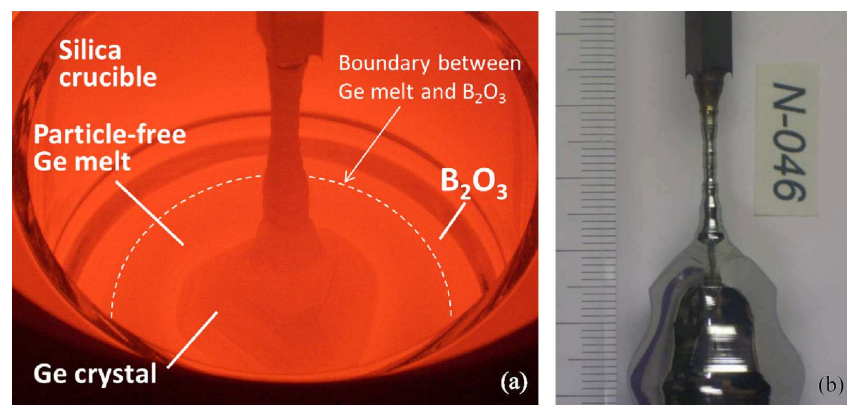

Fig. 2. Photographs (a) during crystal growth from melt partially covered by $\mathrm{B}_{2} \mathrm{O}_{3}$, and (b) of a grown crystal.

\section{Growth of Ge crystals from a melt fully covered by liquid $\mathrm{B}_{2} \mathrm{O}_{3}$}

$\mathrm{B}_{2} \mathrm{O}_{3}$ has an ability to dissolve $\mathrm{GeO}_{2}$-related particles, but the interstitial oxygen concentration in a Ge crystal grown from $\mathrm{B}_{2} \mathrm{O}_{3}$-partially-covered melt was not very high. Assuming that dissolved oxygen atoms evaporated from Ge melt surface in the central region of the crucible, several Ge crystals were grown from a melt fully covered by $\mathrm{B}_{2} \mathrm{O}_{3}$ liquid in order to avoid such evaporation. Ge ingots $(\approx 150 \mathrm{~g})$ were used to charge a silica crucible, and $\mathrm{B}_{2} \mathrm{O}_{3}$ chunks $(20 \mathrm{~g})$ were placed on the $\mathrm{Ge}$ ingots. $\mathrm{GeO}_{2}$ powder (at levels from 0 to 0.20 at.\% in melt) with a purity of $5 \mathrm{~N}$ was added to the crucible, along with the $\mathrm{Ge}$ ingots and $\mathrm{B}_{2} \mathrm{O}_{3}$ chunks. Five [111]-oriented Ge crystals, 1 inch in diameter, were grown at a pulling rate of $10 \mathrm{~mm} / \mathrm{h}$. The detailed growth conditions were comparable to those used to the growth from partially$-\mathrm{B}_{2} \mathrm{O}_{3}$-covered melt.

It was found that Ge crystals could be grown through the $\mathrm{B}_{2} \mathrm{O}_{3}$ layer as shown in Fig. 3a. The [111]-oriented Ge crystal shown in Fig. 3b was grown from a melt fully covered by $\mathrm{B}_{2} \mathrm{O}_{3}$. Any attachment or inclusion of $\mathrm{GeO}_{2}$ -related particles or $\mathrm{B}_{2} \mathrm{O}_{3}$ solid would have occurred on 

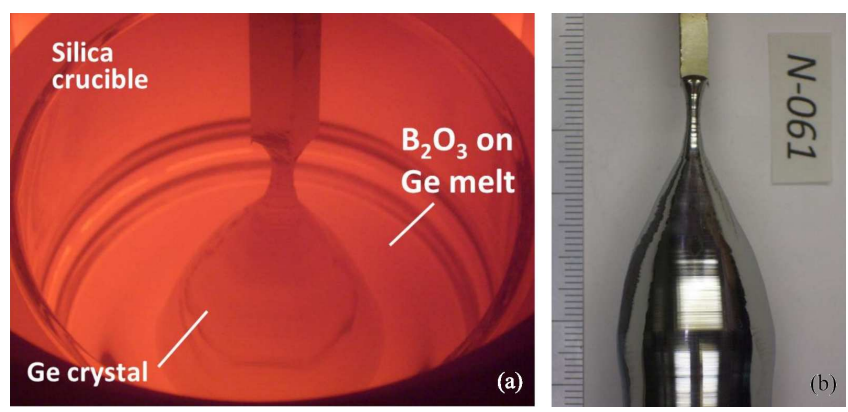

Fig. 3. Photographs (a) during crystal growth from melt fully covered by $\mathrm{B}_{2} \mathrm{O}_{3}$, and (b) of a grown crystal.

the crystal surface, but the surface was very clean. Three habit lines were identified on the crystal surface. The dislocation density in the top portion of the grown crystals, as shown in Fig. 3b, was about $1 \times 10^{3} \mathrm{~cm}^{-2}$. In the case where the $\mathrm{GeO}_{2}$ powder was added at 0.20 at.\%, the dislocation density was lower than $5 \times 10^{2} \mathrm{~cm}^{-2}$.

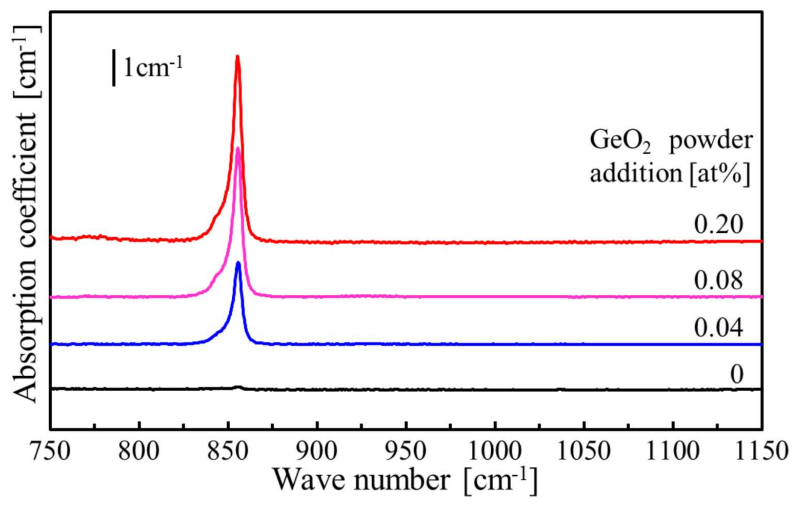

Fig. 4. Infrared absorption spectra of $\mathrm{Ge}$ crystals grown from melt fully covered by $\mathrm{B}_{2} \mathrm{O}_{3}$ measured at RT.

The interstitial oxygen concentration in the as-grown crystals was evaluated by the infrared absorption band at $855 \mathrm{~cm}^{-1}$ due to the antisymmetric $\left(\nu_{3}\right)$ stretching mode at room temperature (RT) using the calibration coefficient of $1.05 \times 10^{17} \mathrm{~cm}^{-2}$ [16]. Figure 4 shows the infrared absorption spectra in the range $750-1150 \mathrm{~cm}^{-1}$ of crystals grown from $\mathrm{B}_{2} \mathrm{O}_{3}$ fully covered melt, with different amounts of added $\mathrm{GeO}_{2}$ powder. No remarkable enhancement of absorption peak height at $855 \mathrm{~cm}^{-1}$ could be detected when $\mathrm{GeO}_{2}$ powder was not added to a fully $\mathrm{B}_{2} \mathrm{O}_{3}$-covered melt. On the other hand, the peak developed remarkably with increasing amounts of added $\mathrm{GeO}_{2}$ powder. It was found that the interstitial oxygen concentration in as-grown crystals was between $1 \times 10^{16}$ and $5 \times 10^{17} \mathrm{~cm}^{-3}$ and this concentration increased as the amount of added $\mathrm{GeO}_{2}$ powder was increased. These results indicate that there are two key aspects to enhancing the interstitial oxygen concentration in Ge crystals: one is that the Ge melt is fully covered by $\mathrm{B}_{2} \mathrm{O}_{3}$, and the other is that $\mathrm{GeO}_{2}$ powder is added to the Ge melt.
The effect of $\mathrm{B}_{2} \mathrm{O}_{3}$ is very similar to that used in LEC growth, i.e., evaporation of dissolved oxygen atoms from $\mathrm{GeO}_{2}$ can be prevented by a full covering of $\mathrm{B}_{2} \mathrm{O}_{3}$ liquid on the Ge melt surface.

The carrier concentration in the grown crystals after the annihilation of oxygen-related thermal donors was $10^{14} \mathrm{~cm}^{-3}$. All crystals exhibited $n$-type conduction after post-annealing, and the $\mathrm{B}$ concentration in all crystals was lower than the detection limit of SIMS analysis of $2 \times 10^{15} \mathrm{~cm}^{-3}$. With regard to other notable features, as shown in Fig. 4, no absorption peaks were observed at $1106 \mathrm{~cm}^{-1}$ related to the $\nu_{3}$ stretching mode of $\mathrm{Si}-\mathrm{O}-\mathrm{Si}$ quasi-molecules in any of the infrared spectra. In addition, no peaks were also observed at $1225 \mathrm{~cm}^{-1}$ related to $\mathrm{SiO}_{2}$ precipitates [17]. These indicate that $\mathrm{Si}-\mathrm{O}$-related defects were lower than the detection limit for all the $\mathrm{Ge}$ crystals.

\section{Reactions between the Ge melt, $\mathrm{B}_{2} \mathrm{O}_{3}, \mathrm{GeO}_{2}$, and $\mathrm{SiO}_{2}$ during the growth}

Reactions during crystal growth can be explained by the Gibbs standard free energy of the relevant oxides at the melting point of $\mathrm{Ge}$ [18]. The Gibbs standard free energy of $\mathrm{B}_{2} \mathrm{O}_{3}$ formation $(-6.50 \mathrm{~kJ} / \mathrm{mol})$ is lower than that of $\mathrm{GeO}_{2}(-3.41 \mathrm{~kJ} / \mathrm{mol})$ at the melting point of $\mathrm{Ge}$. Assuming that free $\mathrm{B}$ atoms are formed from $\mathrm{B}_{2} \mathrm{O}_{3}$ near the $\mathrm{B}_{2} \mathrm{O}_{3} / \mathrm{Ge}$ melt interface, it can be understood that $\mathrm{GeO}_{2}$ particles are dissociated by such free $\mathrm{B}$ atoms. Then, free $\mathrm{B}$ atoms form $\mathrm{B}_{2} \mathrm{O}_{3}$ with free oxygen atoms. Here, considering that the interstitial oxygen atoms in Ge crystals increased as the amount of $\mathrm{GeO}_{2}$ powder added was increased, free oxygen atoms are formed during dissolution of some $\mathrm{GeO}_{2}$ molecules by free $\mathrm{B}$ atoms. Finally, some quantity of the free oxygen atoms so formed might segregate into a grown crystal.

With regard to the low contamination of Si atoms from the silica crucible in Ge crystals, the Gibbs standard free energy of $\mathrm{SiO}_{2}(-6.80 \mathrm{~kJ} / \mathrm{mol})$ is more stable than that of $\mathrm{B}_{2} \mathrm{O}_{3}$. Therefore, $\mathrm{SiO}_{2}$ is thermodynamically stable, and no reaction between the silica crucible and the Ge melt or $\mathrm{B}_{2} \mathrm{O}_{3}$ would have occurred. If some $\mathrm{Si}$ atoms are dissolved in the Ge melt covered by $\mathrm{B}_{2} \mathrm{O}_{3}$, free $\mathrm{B}$ atoms would be formed and then segregated into the grown crystal so that it would exhibit $p$-type conduction. Some quantitative analyses of reactions during the growth are now in progress and will be reported soon.

To summarize, liquid $\mathrm{B}_{2} \mathrm{O}_{3}$ acts not only for the dissolution of $\mathrm{GeO}_{2}$-related particles but also like a convenient catalyst to prevent heavy contamination of the crystal by $\mathrm{B}$ and $\mathrm{Si}$ atoms during the growth. This effect of $\mathrm{B}_{2} \mathrm{O}_{3}$ is quite different to that in LEC growth.

\section{Current and future research related to $\mathrm{CZ}-\mathrm{Ge}$ crystals grown using $\mathrm{B}_{2} \mathrm{O}_{3}$}

Recently the effect of oxygen doping in CZ-Ge crystals grown using $\mathrm{B}_{2} \mathrm{O}_{3}$ on the immobilization of dislocations 
was reported [19]. It was found that oxygen impurities interstitially dissolved in Ge segregate preferentially on dislocations and immobilize them. That is, oxygen atoms in Ge crystals have a similar effect to those in CZ-Si crystals. On the other hand, oxygen-related thermal donors in CZ-Ge crystals grown using $\mathrm{B}_{2} \mathrm{O}_{3}$ have also been investigated [20-22]. The thermal donors are formed by annealing at $300-450^{\circ} \mathrm{C}$, and the number of oxygen atoms occupied by each thermal donor is estimated to be 16 19 [22]. This result corresponds well with, or is slightly higher than, the previous data [23, 24].

These research investigations can be achieved by using oxygen-enriched CZ-Ge crystals, grown by the present technique, with low dislocation density. In the future, various other research studies, such as investigation of the interaction between oxygen and dopant atoms, the precipitation of oxygen-related defects, and so on, will be performed using CZ-Ge crystals. Applications of the technology, in areas such as solar cells and other electrical devices using such Ge crystals with high mechanical strength are expected in the near future.

\section{Summary}

Based on problems arising from the generation of particles in the Ge melt, CZ-Ge crystal growth using $\mathrm{B}_{2} \mathrm{O}_{3}$ has been developed as one improvement to the growth technique. The results of the study are improved techniques that enable dislocation-free and/or oxygen enriched Ge crystal growth. The addition of $\mathrm{B}_{2} \mathrm{O}_{3}$ and $\mathrm{GeO}_{2}$ powder leads to the growth of high quality Ge crystals with high mechanical strength. Several reactions which take place during the growth are discussed, and it is found that liquid $\mathrm{B}_{2} \mathrm{O}_{3}$ acts not only to dissolve $\mathrm{GeO}_{2}$-related particles but also like a convenient catalyst to prevent heavy contamination of the crystal by $\mathrm{B}$ and $\mathrm{Si}$ atoms during the growth. If other useful combinations, similar to that of molten $\mathrm{Ge}$ and liquid $\mathrm{B}_{2} \mathrm{O}_{3}$, are found for $\mathrm{CZ}$ crystal growth, it will lead to the development of a new type functional crystal using an improved $\mathrm{CZ}$ technique. We hope that the $\mathrm{CZ}$ technique will be used indefinitely and will evolve and be improved according to the specific properties, uses, and applications of the required crystals.

\section{Acknowledgments}

This work was supported in part by a Grant-in-Aid for Science Research (20760003 and 22686002) from the Ministry of Education, Science, Sports and Culture. This work was also performed under the Inter-university Cooperative Research Program of the Institute for Materials Research, Tohoku University.

\section{References}

[1] J. Czochralski, Z. Phys. Chem. 92, 219 (1918).

[2] J.B. Mullin, B.W. Straugham, W.S. Brickell, J. Phys. Chem. Solids 26, 782 (1965).
[3] C. Hannig, G. Schwichtenberg, E. Buhrig, G. Gärtner, Mater. Sci. Eng. B 66, 97 (1999).

[4] A. Seidl, S. Eichler, T. Flade, M. Jurisch, A. Kohler, U. Kretzer, B. Weinert, J. Cryst. Growth 225, 561 (2000).

[5] W. Zulehner, D. Huber, Crystal Growth Properties and Applications, Ed. J. Grabmaier, Vol. 8, Springer Verlag, New York 1988, p. 1.

[6] I. Yonenaga, T. Taishi, X. Huang, K. Hoshikawa, J. Appl. Phys. 89, 5788 (2001).

[7] M. Imai, K. Sumino, Philos. Mag. A 47, 599 (1983).

[8] I. Yonenaga, K. Sumino, J. Appl. Phys. 80, 734 (1996).

[9] B. Depuydt, M. Jonghe, W. Baets, GermaniumBased Technologies, Eds. C. Claeys, E. Simoen, Elsevier, Oxford (UK) 2007, p. 17.

[10] B. Depuydt, A. Theuwis, I. Romandic, Mater. Sci. Semicond. Process. 9, 437 (2006).

[11] W. Guter, J. Schone, S.P. Philipps, M. Steiner, G. Siefer, A. Wekkeli, E. Welser, E. Oliva, A.W. Bett, F. Dimoroth, Appl. Phys. Lett. 94, 223504 (2009).

[12] T. Taishi, Y. Murao, Y. Ohno, I. Yonenaga, J. Cryst. Growth 311, 59 (2008).

[13] T. Taishi, Y. Ohno, I. Yonenaga, Thin Solid Films 518, 2409 (2010).

[14] T. Taishi, Y. Ohno, I. Yonenaga, J. Cryst. Growth 311, 4615 (2009).

[15] T. Taishi, Y. Hashimoto, H. Ise, Y. Murao, T. Ohsawa, I. Yonenaga, J. Cryst. Growth 360, 47 (2012).

[16] V.V. Litvinov, B.G. Svensson, L.I. Murin, J.L. Lindström, V.P. Markevich, A.R. Peaker, J. Appl. Phys. 100, 033525 (2006).

[17] T. Taishi, H. Ise, Y. Murao, T. Ohsawa, M. Suezawa, Y. Tokumoto, Y. Ohno, K. Hoshikawa, I. Yonenaga, J. Cryst. Growth 312, 2783 (2010).

[18] I. Barin, Thermochemical Data of Pure Substances, Part I and Part II, VCH, Weinheim 1989.

[19] Y. Murao, T. Taishi, Y. Tokumoto, Y. Ohno, I. Yonenaga, J. Appl. Phys. 109, 113502 (2011).

[20] T. Taishi, Y. Hashimoto, H. Ise, Y. Murao, T. Ohsawa, Y. Tokumoto, Y. Ohno, I. Yonenaga, J. Phys. Conf. Ser. 281, 012011 (2011).

[21] I. Yonenaga, T. Taishi, H. Ise, Y. Murao, K. Inoue, T. Ohsawa, Y. Tokumoto, Y. Ohno, Y. Hashimoto, Physica B 407, 2932 (2012).

[22] K. Inoue, T. Taishi, Y. Tokumoto, Y. Murao, K. Kutsukake, Y. Ohno, I. Yonenaga, J. Appl. Phys. 113 073501 (2013).

[23] P. Clauws, P. Vanmeerbeek, Physica B 273-274, 557 (1999).

[24] W. Kaiser, J. Phys. Chem. Solids 23, 255 (1962). 